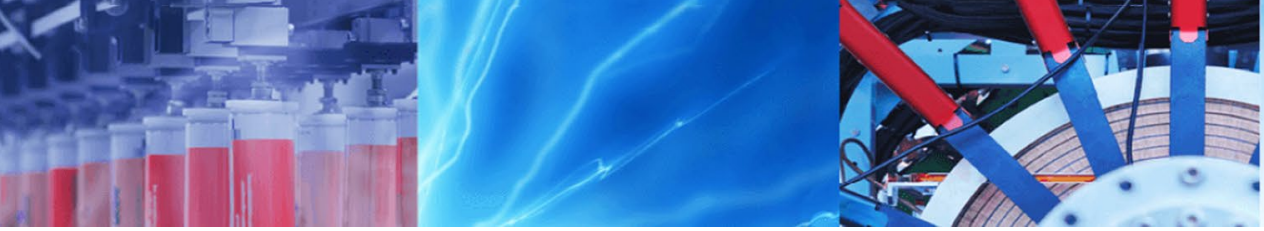

Research Article

\title{
A correlation between microstructure and residual stress in the 6061 Al-Mg-Si alloy with different thermomechanical process
}

\author{
Mariana X. Milagre ${ }^{1}(0) \cdot$ Margareth Franco $^{1} \cdot$ Frederico Genezini $^{1} \cdot$ Robert C. Wimpory $^{2} \cdot$ Fabiano Yokaichiya $^{2}$. \\ Isolda Costa'
}

Received: 28 September 2020 / Accepted: 23 November 2020 / Published online: 28 November 2020

(c) Springer Nature Switzerland AG 2020

\begin{abstract}
Depending on the nature of the loading during service, the level and nature of residual stress can contribute to the lower service-life of a component. In this study the internal level of the residual stress of a $6061 \mathrm{Al}-\mathrm{Mg}$-Si alloy with different thermomechanical processes was evaluated by residual stress neutron diffraction (RSND). Commercial tempers such as T6 (peak aged) and O (annealed) were compared with the 6061 alloy after different steps of a thermomechanical processing used for the manufacturing of nuclear fuel plates, $\mathrm{R} 3$ and $\mathrm{R} 9 \mathrm{H} 60$. The results showed that the lowest level of residual stress was found for the peak age, T6 condition. This was associated with the highest microhardness value (highest density of " $\beta$ " phase) and lowest grain size. The $O$ temper was the only condition which showed compressive residual stress and the most coarsened precipitates. The nuclear thermomechanical processes, R3 and R9H60, resulted in increased level residual stress related to the T6 and showed a tensile nature in relation to its parent material (6061-0). Moreover, the RSND technique allows observing that the texture is also higher for the samples processed by the nuclear thermomechanical process due the hot rolling stage.
\end{abstract}

Keywords Aluminum alloy $\cdot$ Microstructural characterization $\cdot$ Neutron diffraction $\cdot$ Residual stress

\section{Introduction}

The 6061 aluminum alloy is widely used in the automotive, offshore, aircraft, construction and nuclear industries due to its good mechanical properties and corrosion resistance compared to other Al series alloys [1]. The good mechanical properties of this alloy are related to precipitation hardening resulting mainly from the " $\beta$ " $\left(\mathrm{Mg}_{5} \mathrm{Si}_{6}\right)$ phase. This phase has a needle-like morphology, coherent with the matrix and aligned parallel to $\langle 100\rangle_{a}$. It precipitates at temperatures in the range from 125 to $200^{\circ} \mathrm{C}$ [2-11]. The 6061-T6 temper is the peak-aged condition of this alloy. It involves a solution heat treatment step, followed by quenching and aging in the $175-180^{\circ} \mathrm{C}$ range for $10-20 \mathrm{~h}$ $[3,12]$. This alloy might be used when strengthening is a requirement. On the other hand, the $O$ temper corresponds to the annealed condition to obtain the lowest strength temper, being extremely ductile and suitable for forming process [1]. As it can be seen, different thermomecanical processes can be adopted in order to obtain suitable alloy properties depending on their application.

Thermomechanical processes are responsible for modifications in microstructure features of the Al alloys. According to previous work [13], heating and rolling processes alter the microstrucure of the 6061 alloy and, consequently, its corrosion resistance and strength. Despite the efforts to control manufacturing parameters to guarantee an optimal microstructure, all materials present some level of residual stress.

$\triangle$ Mariana X. Milagre, marianamilagre@yahoo.com.br| ${ }^{1}$ Instituto de Pesquisas Energéticas e Nucleares - IPEN/CNEN, Av. Prof. Lineu Prestes, 2242, São Paulo, Brazil. ${ }^{2}$ Helmholtz-Zentrum Berlin für Materialien und Energie, Glienicker Strasse 100, 14109 Berlin, Germany. 
The combination of the residual stress and the loading in service can be detrimental to the component performance. Thermomechanical processes such as heating, forming, and welding, contribute to non-uniform plastic deformations due to misfiting between different parts of a component and/or metallurgical phenomena occurring into the material structure (phase precipitation/dissolution, grain shape modifications, dislocation generation/ aniquilation, etc.,) $[14,15]$. The combination of these effects in a multi-phase material might contribute to its sudden failure in service, once each phase has its own physical and mechanical properties [14, 15]. Therefore, it is important to know how different thermomechanical processes affect the level of residual stress in the material.

Residual stress is an extrinsic property of a material. Therefore, it cannot be directly measured. However, diffraction techniques can evaluate the level of residual stress by measuring the level of deformation [14]. These techniques are based on measuring the material interplanar spacing, for different orientations, according to the Bragg's law, by an incident beam with a known wavelength. The neutral diffraction technique is an advantageous method once the beam penetrates an order of centimeters into the material, generating precise information from the bulk stress state [14, 16-19].

Despite the limited access to nuclear reactors, the use of neutron diffraction techniques to evaluate the level of residual stress in the $6061 \mathrm{Al}-\mathrm{Mg}-\mathrm{Si}$ alloy processed by different thermomechanical treatments has been largely reported [20-23]. Camak et al. [24] used this technique to study the texture dominating the structure of ultrasonic additively-manufactured 6061 alloy. Texture analysis of the welded 6061-T6 alloy was performed by Woo et al. [25]. Bardel et al. [26] used the technique in order to quantify the level of residual elastic strain of an electron beam fusion welded 6061 alloy, and the results showed good agreement with a proposed modeling approach using two slightly different spraying techniques. This technique was also used to validate modeling thickness stress profiles of the 6061 alloy after a coating deposition method (cold spray technique) $[27,28]$. Chen and Kovacevic [29] used neutron diffraction associated to finite element modeling to perform thermo and thermomechanical analysis of a friction stir welded 6061-T6 alloy. Additionally, this technique can also be applied to phase determination, as reported by Dye et al. [19], who used the technique to investigate phase evolution in a welded mild steel. The technique has also found application in the measurements of thermal $[18,30]$ and severe thermomechanical effects [31] on the materials structure.

The 6061 alloy with different thermomechanical conditions is used in nuclear research fuel reactors, either in the 6061-T6 condition (commercial one) or after different sequences of heating and hot or cold rolling. Consequently, different levels of residual stress are found in the nuclear components structure, and it can affect the component performance in service. Information about the internal residual state of the 6061 alloy applied in nuclear research reactors has not been reported. In this study, the internal residual stress of the 6061 alloy treated by different thermomechanical processes was analyzed, and the results compared with that of the commercial T6 (peakaged) and $\mathrm{O}$ (annealing) conditions by the ND technique. The results were correlated with the microstructural modifications related with each process.

\section{Experimental}

\subsection{Material}

The chemical composition of the 6061 alloy used in this study was obtained by inductively coupled plasma-optical emission spectrometry (ICP-OES) and it is as follows: Al 89.9 wt\%, Cr 0.10 wt $\%$, Cu 0.22\%, Fe 0.20 wt\%, Mg 0.90 wt\%, Mn 0.05 wt\%, Si 0.13 wt $\%$ and Zn 0.02 wt \%. Samples were obtained from different thermomechanical processes summarized in Table 1.

\subsection{Microstructural characterization}

6061 samples were metallographically prepared by sequentially grinding using SiC papers ( $\# 500, \# 800, \# 1200$, \#2500 and \# 4000) followed by polishing with diamond suspensions of $3 \mu \mathrm{m}$ and $1 \mu \mathrm{m}$. Etching to reveal the grains morphology and size was performed by immersion in $10 \%$
Table 1 The 6061 alloy samples processing description

\begin{tabular}{ll}
\hline Thermomechanical process & Description \\
\hline T6 & Solubilization followed by artificial aging (commercial temper) \\
$\mathrm{O}$ & Solubilization followed by annealing (commercial temper) \\
${ }^{*} \mathrm{R} 3$ & From O temper, hot rolled at $440^{\circ} \mathrm{C}(15 \mathrm{~min})$ in 3 passes \\
${ }^{*} \mathrm{R} 9 \mathrm{H} 60$ & From R3 process, hot rolled at $440^{\circ} \mathrm{C}(15 \mathrm{~min})$ in 9 passes fol- \\
& lowed by heating $440^{\circ} \mathrm{C}$ for $60 \mathrm{~min}$ \\
\hline
\end{tabular}

${ }^{*} R=$ rolling; $H=$ heating 
$\mathrm{NaOH}$ solution at $60^{\circ} \mathrm{C}$ for $30 \mathrm{~s}$, followed by immersion in $30 \% \mathrm{HNO}_{3}$ solution for $30 \mathrm{~s}$ then immersion in $100 \mathrm{~mL}$ solution with $4 \mathrm{~g}$ of $\mathrm{KMnO}_{4}$ and $1 \mathrm{~g}$ of $\mathrm{NaOH}$. Grain size was estimated using image analyzer software. Finally, hardness tests were carried out at the sample surface using a Buehler's macrohardness equipment, recording 30 random measurements with a load of $200 \mathrm{gf}$ and a dwell time of $10 \mathrm{~s}$.

\subsection{Neutron diffraction characterization}

Residual stress neutron diffraction (RSND) was carried out for the 6061 samples using the on the Instrument E3 of the research reactor BER II at the Helmholtz-Zentrum Berlin (HZB). The diffraction pattern was measured for the lattice planes $\{211\}$ and $\{311\}$ for Al. The initial gauge volume used was of $4 \times 2 \times 2 \mathrm{~mm}^{3}$ and then $10 \times 2 \times 2 \mathrm{~mm}^{3}$ to increase grains and in order to obtain good signal intensity. Once that microstructural changes were involved during the thermomechanical processing, it was assumed that the normal stress is $0 \mathrm{MPa}$ to calculate the in-plane stress. In general, a centered scan from left to right should remove the symmetrical surface effect, when summing the peaks. However, a further identical scan was made with the sample rotated $180^{\circ}$ in the beam in order to confirm the results. The transverse and axial strain pairs are then averaged. The experiments were performed using neutron wavelength of $0.147 \mathrm{~nm}$ and. Figure 1 shows the samples configuration for the measurements. All specimens were centered and scanned in discrete steps of $1 \mathrm{~mm}$.

The lattice spacing variations were determined by measuring the shift of the scattering angle $\theta^{\text {hkl }}$. The Bragg's law is given by:

$n \lambda=2 d \sin \theta$

where $\lambda$ is the wavelength of the neutrons. The elastic strain, $\varepsilon^{\mathrm{hkl}}$, can be calculated by:

$\varepsilon=\frac{\Delta d}{d_{0}}=\frac{d-d_{0}}{d_{0}}=\frac{\sin \theta_{0}}{\sin \theta}-1$

Finally, the residual stress is given by:

$\sigma_{i}=\frac{E}{1+v} \varepsilon+\frac{v E}{(1+v)(1+2 v)}+\left(\varepsilon_{1}+\varepsilon_{2}+\varepsilon_{3}\right)$

The Young's and Poisson's ratio modulus values used were $69 \mathrm{GPa}$ and 0.33 , respectively.

\section{Results and discussion}

Thermomechanical processes resulted in changes in grain morphology and size of the 6061 alloy, Fig. 2. In relation to the commercial tempers, $\mathrm{T} 6$ and $\mathrm{O}$, the nuclear processing corresponding to $\mathrm{R} 3$ and $\mathrm{R} 9 \mathrm{H} 60$ were associated to grain coarsening and it can be related to the hot rolling
Fig. 1 Configuration of the samples during RSND measurements. a Schematic diagram of the sample measurements orientation, $\mathbf{b}$ strain measurement in transverse orientation and $\mathbf{c}$ strain measurement axial orientation
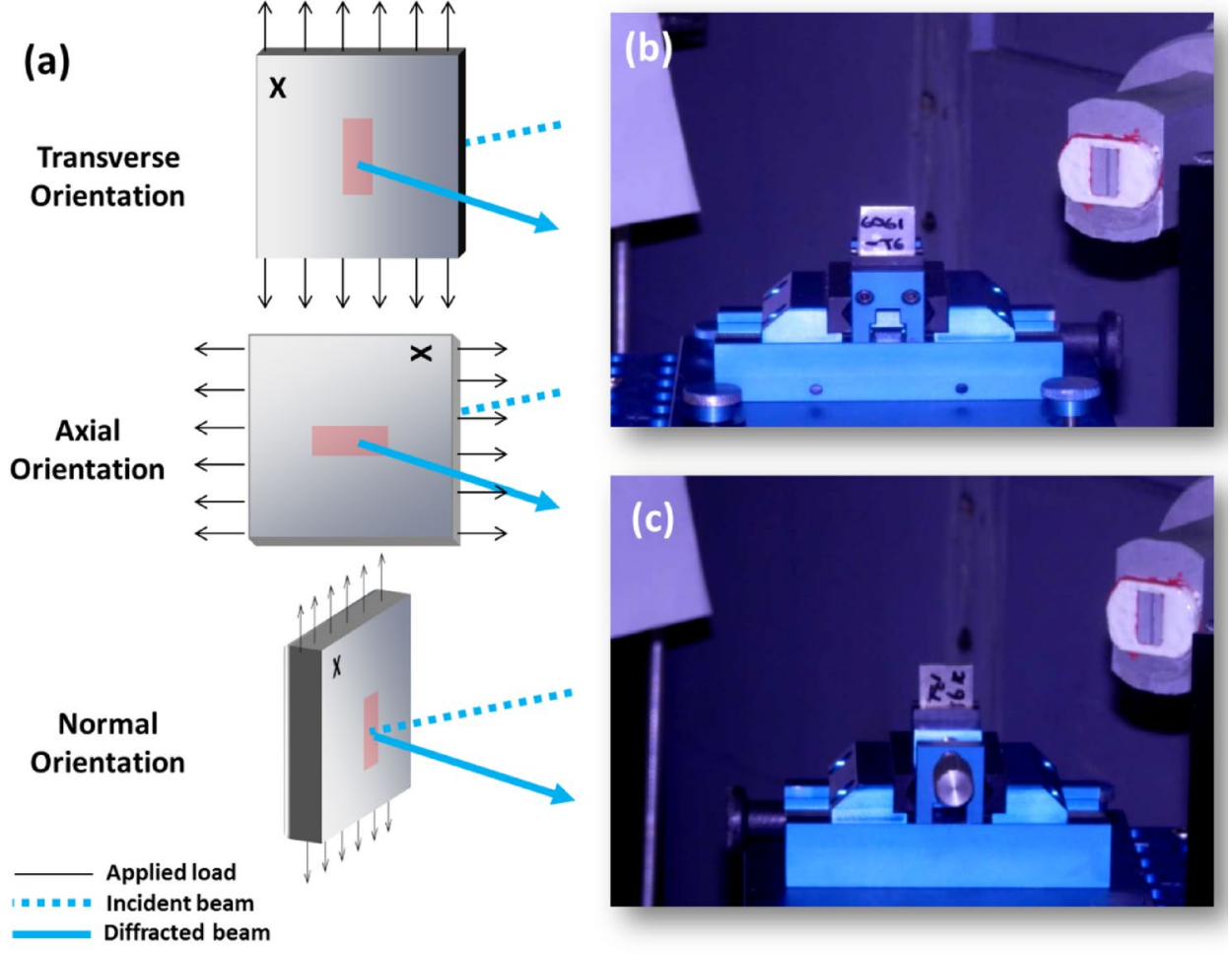

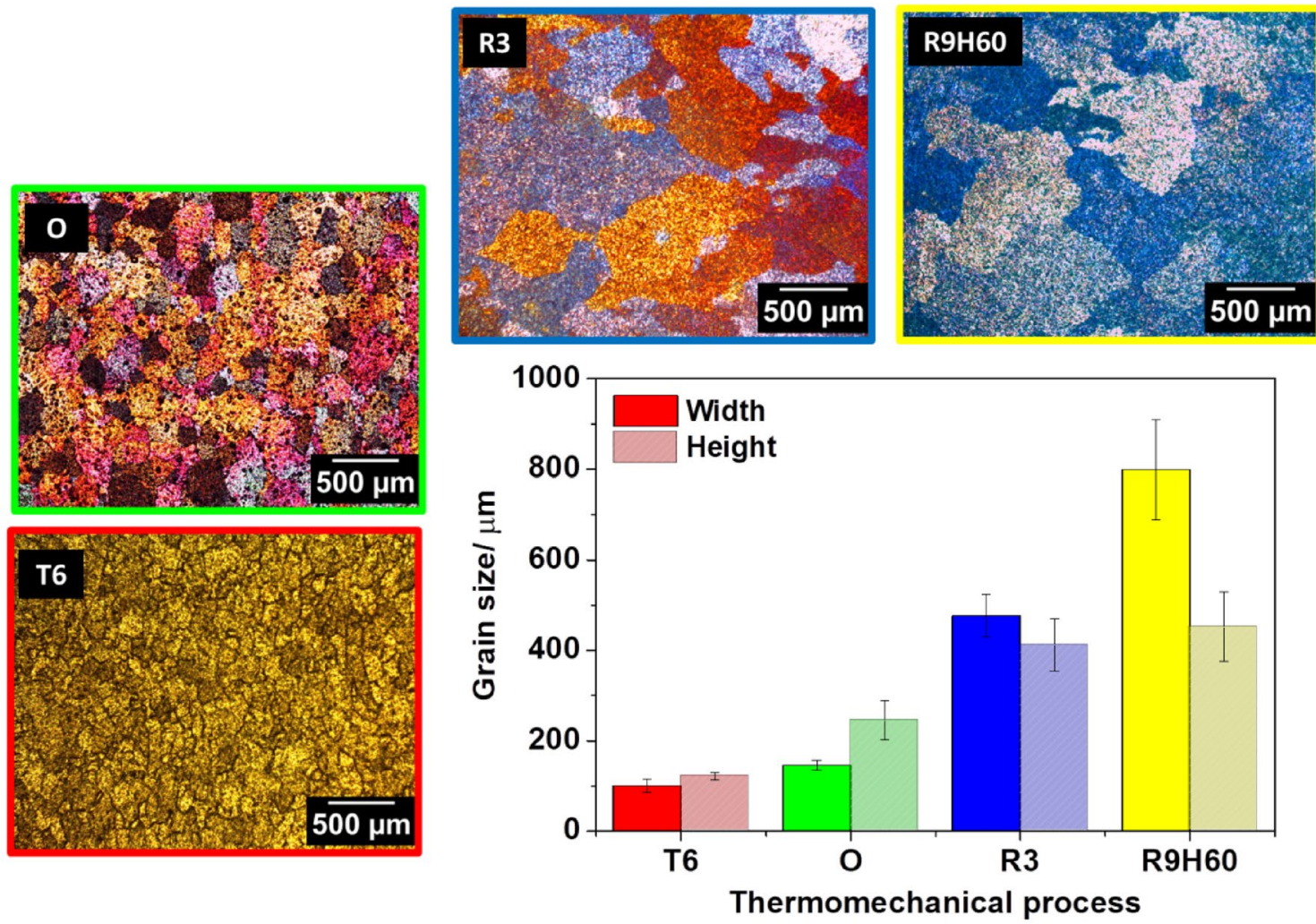

Fig. 2 Optical micrographs of the 6061 alloy after different thermomechanical processes and their respective grain sizes

process. The largest grain sizes were found related to the $\mathrm{R} 9 \mathrm{H} 60$ condition and this is explained by the heating step for $60 \mathrm{~min}$ after the hot rolling stage.

Coarse phases were observed by Optical Microscopy, as illustrated in Fig. 3. It shows optical micrographs corresponding to the various tested conditions. The grain boundaries corresponding to T6 condition are easily revealed by etching, but it was difficult to observe the grain boundaries corresponding to the $\mathrm{O}, \mathrm{R} 3$ and $\mathrm{R} 9 \mathrm{H} 60$ conditions, mainly due to etching pits. These pits are formed by the preferential attack of coarse precipitates which were etched out [32]. The largest etching pits were observed in the $\mathrm{O}$ temper condition, corresponding to the most coarsened precipitates among the tested ones.

Figure 4 shows the results of hardness measurements. A significant decrease in hardness was observed for the nuclear thermomechanical processing in relation to the commercial T6 temper. It is known that a high density of the fine needle-shaped " $\beta$ " precipitate is responsible for strengthening of $6 \mathrm{xxx}$ aluminum alloys. The T6 temper is the peak-aged condition and, consequently, high hardness was expected for this condition. On the other hand, annealing is a heat treatment applied before any forging process in order to favor uniform distortion and to prevent the alloy of presenting defects and fracture with a common heating temperature about $570^{\circ} \mathrm{C}$, which is kept for 4-6 $h$ [33].As the solvus temperature of the " $\beta$ " phase is below $353^{\circ} \mathrm{C}$, this heat treatment favors the " $\beta$ " dissolution and coarsening of the remaining phases, as indicated by Fig. 3. Thus, lower hardness values are expected for the commercial $O$ temper in relation to the T6 one [21, 22].

Dynamic precipitation and recovery may occur during hot/warm deformation, where hot deformation processes are reported to increase the strength of Al alloys, while warm processes weakened the precipitation hardening effect [34]. As observed by the previously results, Figs. 2 and 3 , the deformation temperature also influences the grain structure. The dynamic recovery and recrystallization process are softening mechanisms, which occur depending on the deformation temperature [34]. The absence of a deformed grain structure after rolling (Figs. 2, 3) and the lower value of hardness for the nuclear thermomechanical processes indicate the occurrence of restoration processes. Since the precipitates will be softer at $440^{\circ} \mathrm{C}$, the temperature is close to the solubilization temperature, they are more easily cropped by dislocations during the deformation. Therefore, the barrier to dislocation motion is not efficient and the hardness of the alloy decrease [35]. Additionally, during the multi-pass rolling the samples were annealed for $15 \mathrm{~min}$ between each pass at $440{ }^{\circ} \mathrm{C}$, 
Fig. 3 Micrographs of the 6061 alloy after different thermomechanical processes at higher magnification than those showed in Fig. 2. a T6 temper $=$ peak age, $\mathbf{b} \mathrm{O}$ temper $=$ annealing, $\mathbf{c} \mathrm{R} 3=3$ passes of hot rolling and $\mathbf{d} \mathrm{R} 9 \mathrm{H} 60=9$ passes of hot rolling and heating for $60 \mathrm{~min}$
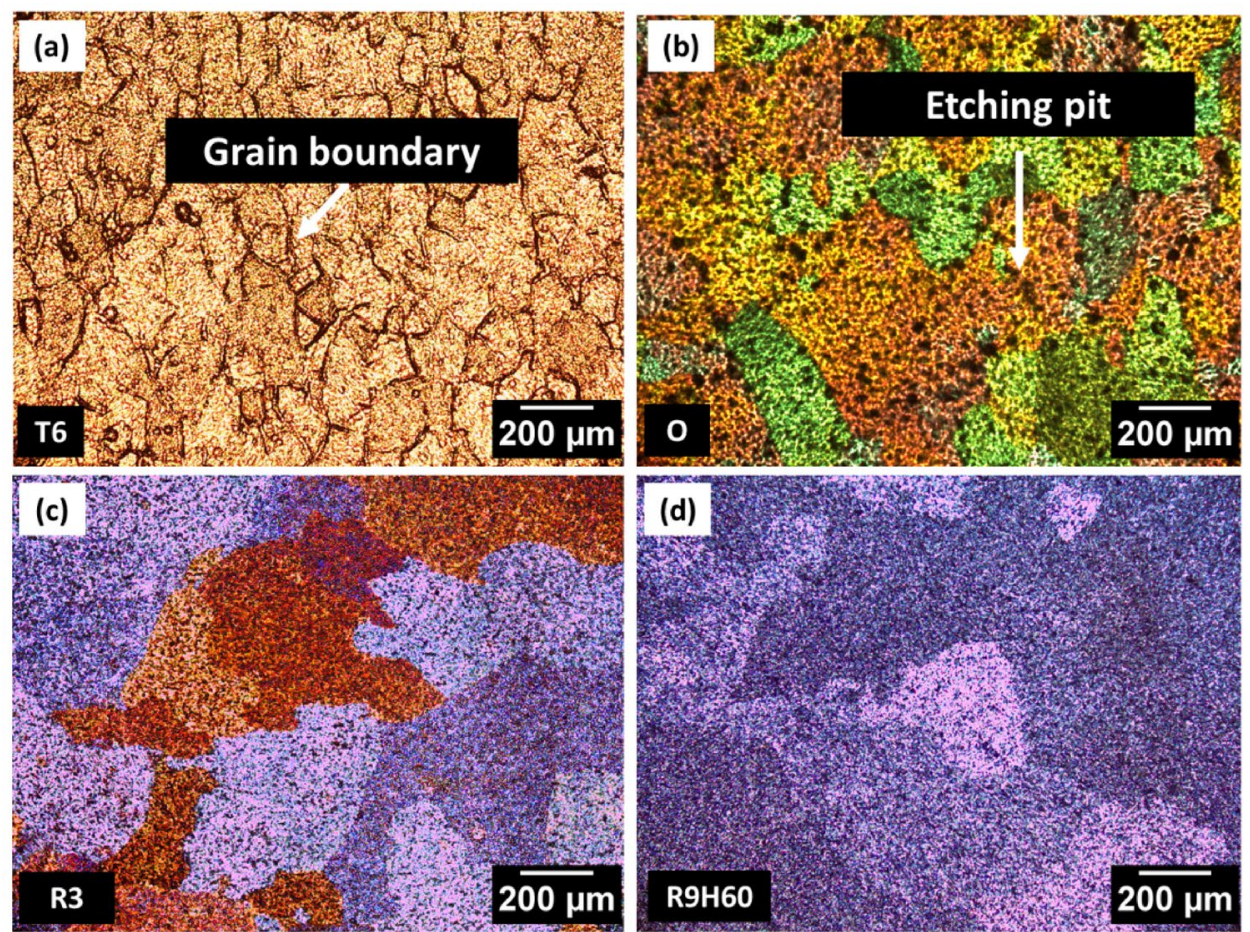

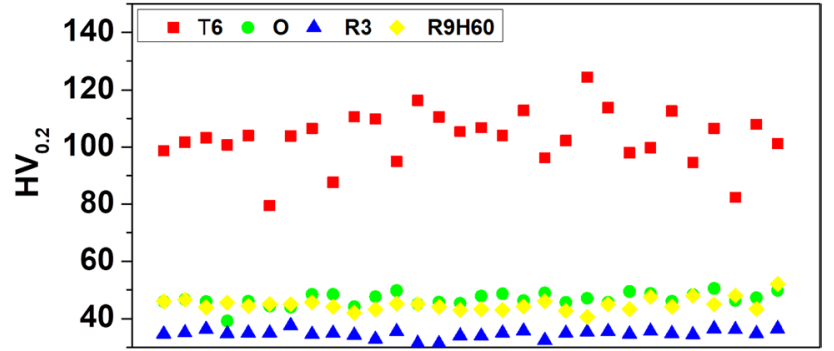

Hardness data set

Fig. 4 Hardness measurements obtained for the 6061 alloy submitted to different thermomechanical processes

and thus, the majority of the stored energy created during deformation is removed. Therefore, the lower total strains exhibited slower kinetics for recovery of the mechanical properties of the alloy. This behavior explains the lower hardness of the R3 condition [36]. However, for the R9H60, despite the interpass annealing step the accumulation of deformation is favored with the rolling passes. The material got resistance to deformation by the increment in the dislocation density, which are not totally annihilated during the dynamic process. As dislocations are preferential sites for " $\beta$ " precipitation, there was an increment in the hardness value for this condition in relation to the R3.

Figures 5, 6 and 7 show the results of neutron diffraction (ND) analysis for the 6061 alloy exposed to the various thermomechanical processes. The diffracted peak

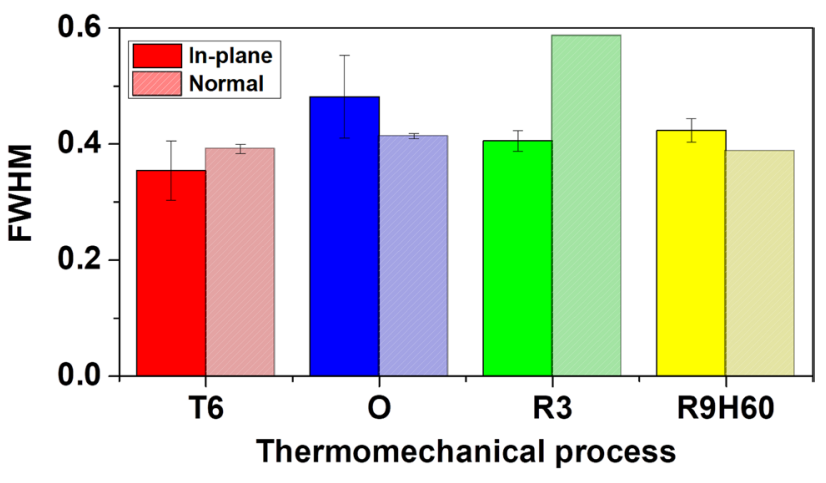

Fig. 5 Full width half maximum (FWHM) values for in-plane (LD and TD average) and normal directions of the $6061 \mathrm{Al}-\mathrm{Mg}-\mathrm{Si}$ alloy submitted to various thermomechanical processes

shift is related to the macrostresses (Type I stresses) and microstresses (Type II stresses) in a material, whereas the peak broadening is related to the microstresses (Type III stresses) $[14,15,37]$. The Type I is associated with external loads or regions of the material with different levels of deformation, for instance, deformations due thermomechanical process as rolling favors the appearance of residual stresses of a different nature (compressive/tensile) from the center to the sample surface. The Type II is associated with elastic and thermal properties of grains with different orientations and/or different phases and phase transformation. In this case, as previously reported, the nuclear thermomechanical processes favor the 


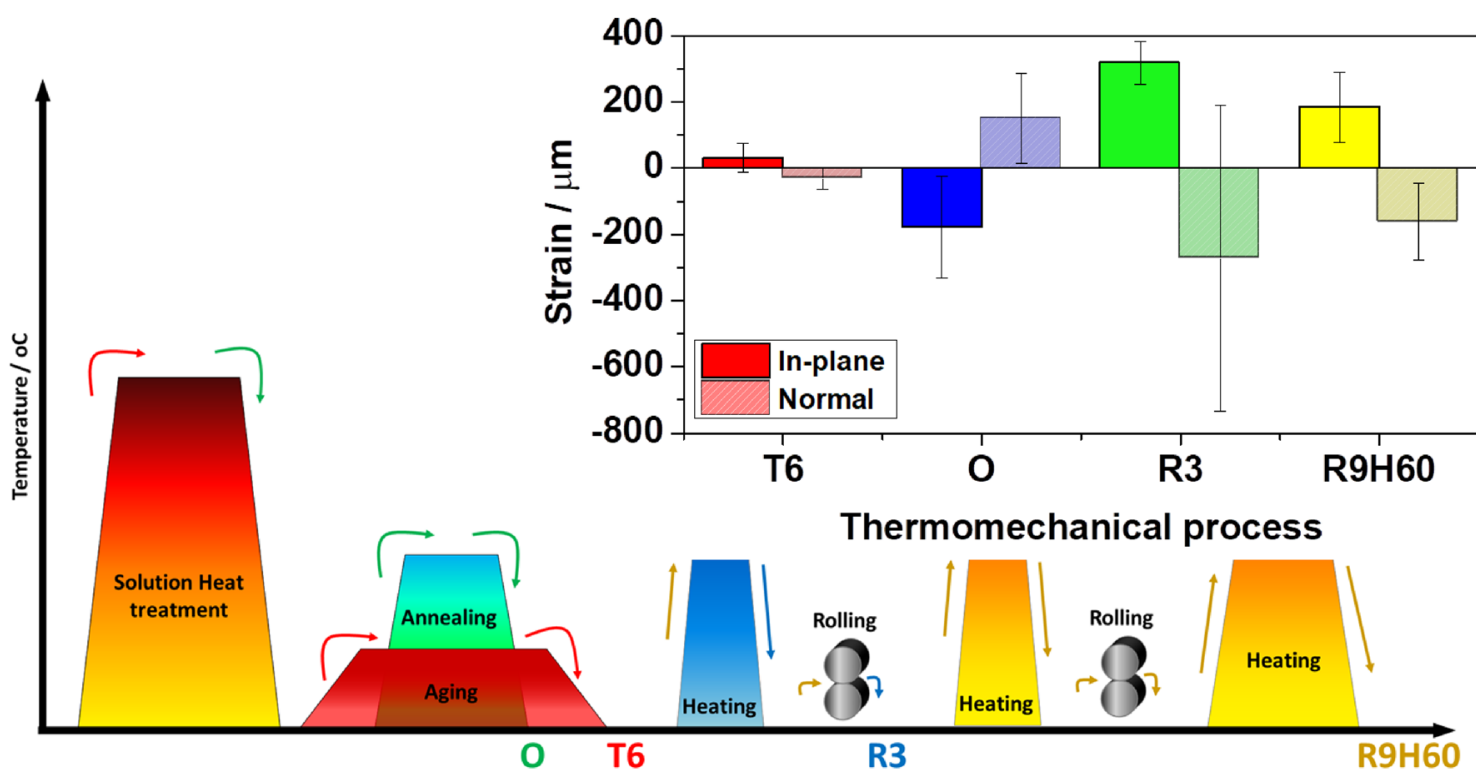

Fig. 6 Residual strain of the (311) in the normal and in-plane orientations dependence of the thermomechanical process for the 6061 Al$\mathrm{Mg}-\mathrm{Si}$

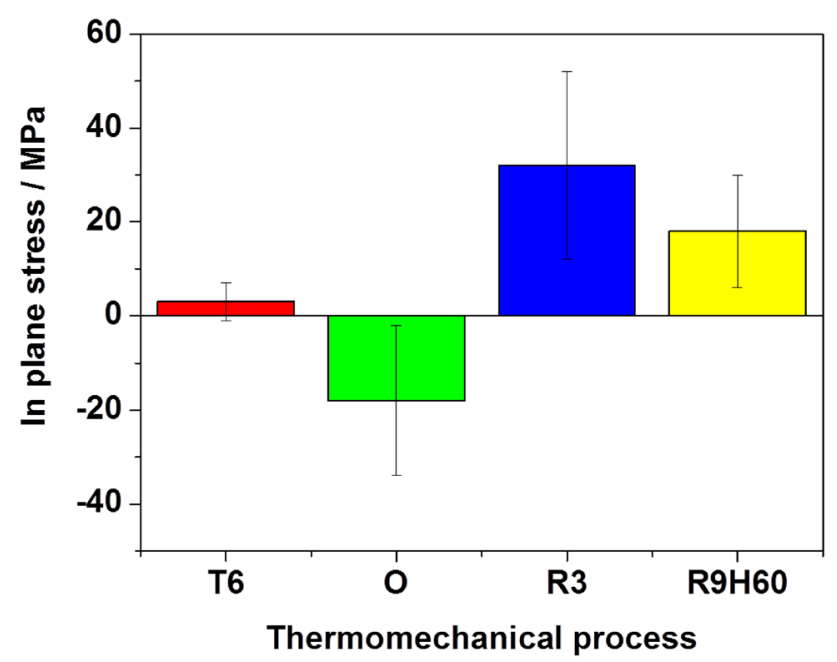

Fig. 7 (311) in-plane residual stress level related to the thermomechanical processes of the $6061 \mathrm{Al}-\mathrm{Mg}-\mathrm{Si}$ alloy used in this study

modifications in the microstructure of the $6061 \mathrm{Al}-\mathrm{Mg}-\mathrm{Si}$ alloy [13,38], influencing the level of residual stress as observed in this work. Finally, the Type III is associated with stresses as a consequence of coherency at interfaces and dislocation stress fields. Figure 5 shows the values of full width at half maximum (FWHM) related to each thermomechanical process.

The narrowest peaks were related to the T6 thermomechanical process. Based on this result a correlation between microhardness and the FWHM can be proposed.
The highest strengthening T6 condition was associated to the lowest FWHM value. This result indicated that " $\beta$ " phase dissolution and phase coarsening associated with $\mathrm{O}, \mathrm{R} 3$ and $\mathrm{R} 9 \mathrm{H} 60$ processes increased the level of residual type III microstress. Additionally, the residual macrostrain and type II microstrain is related to the diffracted peak center (20) location and, according to Bragg's law to the lattice space modification (Eq. 1). Figure 6 presents the relationship between the different thermomechanical processes and the residual strain according to Eq. 2.

The thermomechanical processes produce lattice distortion in the microstructure, and the lattice distortion induces the residual strain. Lattice deformation is induced by defects, such as vacancies and dislocations. Therefore, the differences in the level of residual strain are caused by microstructure modifications related to each thermomechanical process, in which precipitates density, morphology and size, as well as dislocations density should play significant role. The different signs of the in-plane and normal strains are expected in order to maintain the internal balance and the material integrity. Additionally, according to the results, the peak-age (T6) condition showed the lowest values of lattice strain in both, in-plane and normal directions. In this thermomechanical condition, the strengthening nano-sized phases are thin and evenly distributed into the alloy structure. On the other hand, the annealing and nuclear thermomechanical processes favor this phase dissolution and coarsening, as shown by the hardness results. The high temperatures reached during these processes favor coarsening, increasing the 
Fig. 8 Normalized integrated intensity with respect to the gauge volume and monitor count. The samples were analyzed in the transverse (0) and also rotate and analyzed in the axial (90) orientation

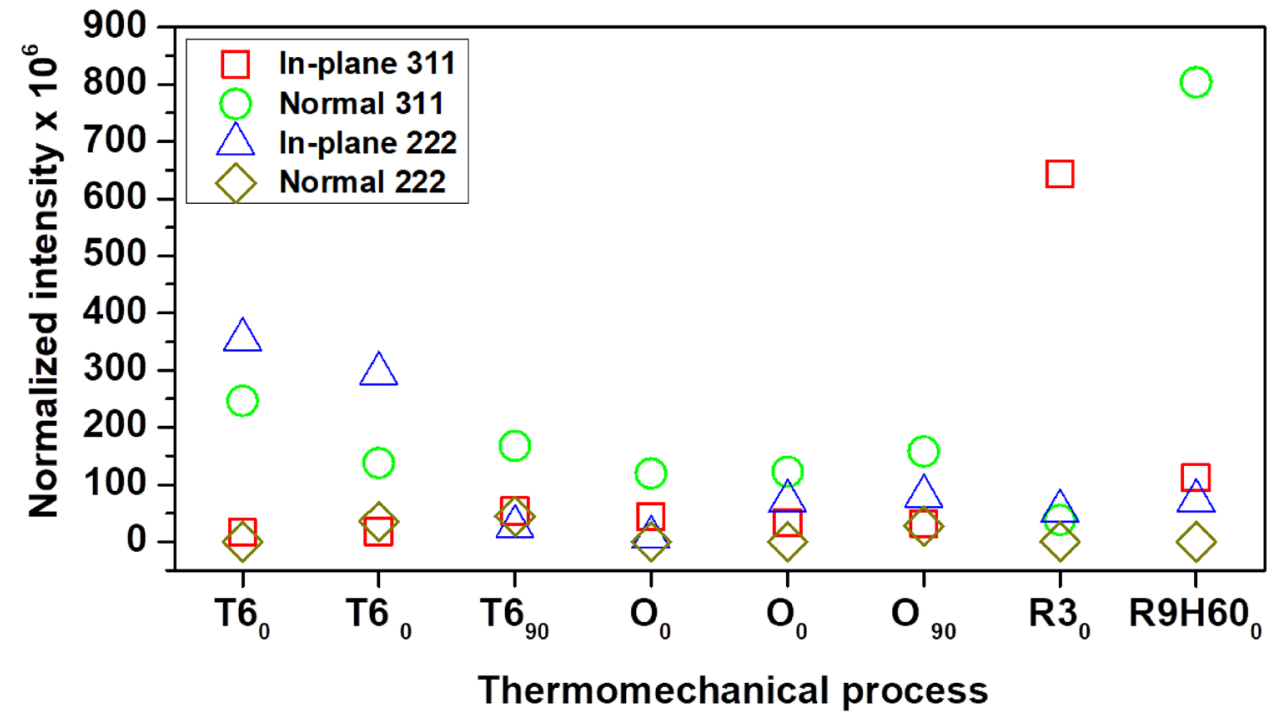

d-lattice value and, consequently, affecting the residual strain. This behavior has also been reported by Cakmak et al. [24]. Based on the residual strain measurements and the physical constants of the material, it was possible to calculate the level of residual stress (Eq. 2) for each thermomechanical condition.

The 6061 alloy is produced by extrusion. According to Honarpisheh et al. [39] during the extrusion process, the residual stress is controlled by mechanical and thermal sources. Considering the extruded material as stacked layers, the outer layers will exert compression on those in the center, when passing from the die. Therefore, compressive stresses will occur in the center and tensile ones appear in the surface. However, after passing through the die, the material in the center will recover its initial condition, whereas the surrounding material will resist to the central material portion accommodation. Thus, under unloading conditions, residual tensile stresses will develop in the center and compressive residual stress will appear at the surface. Besides the mechanical effect, heating also affects the properties. During extrusion, the material reaches temperatures around $400^{\circ} \mathrm{C}$, and during refrigeration, the surface will cool faster than the center. This difference in temperature contributes to tensile residual stress in the center and compressive one at the surface. After extrusion, the alloy is annealed (O temper) or artificially aged (T6). During the $\mathrm{O}$ temper, the alloy reaches a higher temperature but for shorter periods than the T6 temper. This procedure will generate different microstructures, which contributes to different levels of residual stress, as observed in Fig. 7.

According to the results, the T6 peak-age condition, which is related to the highest hardness and density of " $\beta$ " phase, besides the lowest grain sizes, showed the lowest levels of residual stress. On the other hand, the annealed O temper condition with coarsened precipitate, largest etching pits, and larger grain sizes in relation to T6 temper, was the only condition showing compressive residual stress. Finally, thermomechanical processes R3 and R9H60 were related to the highest levels of tensile residual stress, which can be related to the rolling process and thickness reduction. Besides, the differences between $\mathrm{R} 3$ and $\mathrm{R} 9 \mathrm{H} 60$ can be due to the additional heating step of the R9H60 process, which promotes stress relaxation.

The RSND also allows the characterization of the texture of the nuclear thermomechanical process, Fig. 8.

The normalized integrated intensity was calculated by dividing the integrated intensity by the gauge height and monitor count. The hkl 311 texture is very different in the $\mathrm{R} 3$ and $\mathrm{R} 9 \mathrm{H} 60$ which was attributed to the hot rolling step. In general, the hkl 311 normal direction is much stronger than the in-plane direction. The normal hkl 222 texture is very weak, whereas the in-plane hkl 222 is much stronger.

\section{Conclusions}

The use of the neutron diffraction technique (ND) allowed a correlation between microstructure and the internal level of residual stress in the $6061 \mathrm{Al}-\mathrm{Mg}-\mathrm{Si}$ alloy with different thermomechanical processes. The lowest level of residual stress was related to the peak-age commercial T6 condition. This condition was characterized by the lowest grain size and highest microhardness, which is related to the high content of " $\beta$ " phase for this condition. The modifications due the thermomechanical processes which were related to the " $\beta$ " phase dissolution (lower microhardness values), precipitates coarsening and increased in grain sizes were associated to the increased level of residual stress. The nuclear thermomechanical processes, $\mathrm{R} 3$ and $\mathrm{R} 9 \mathrm{H} 60$, favored the development of tensile residual 
stress in the 6061 alloy structure and increased its texture, in relation to their parent material, commercial O temper (annealed) condition. The $\mathrm{O}$ temper was the only condition that presented compressive nature of residual stress, and this thermomechanical process was associated with the coarsest precipitates.

Acknowledgements The authors acknowledge the National Commission for Nuclear Energy (CNEN) in Brazil for financial support to this work and for the Grant of Mariana X. Milagre (SEI 01342.002357/201932). Acknowledgements are due Helmoholtz-Zentrum Berlin, Germany, for technical support with neutron diffraction analysis and to Dr. José A. B. de Souza and Dr. Stela M. C. Fernandes of the Nucleares and Energy Research Institute (CNEN/IPEN) for providing the material used in this study and the technical support about the research nuclear operations.

Funding This study was funded by National Commission for Nuclear Energy (CNEN) in Brazil (SEl 01342.002357/2019-32).

\section{Compliance with ethical standards}

Conflict of interest The authors declare that they have no conflict of interest.

\section{References}

1. ASM Handbook Properties and selection: Nonferrous alloys and Special-purpose Materials, ASM International (2001). http:// books.google.com.hk/books?id=eC-Zt1J4oCgC

2. Edwards GA, Stiller K, Dunlop GL, Couper MJ (1998) The precipitation sequence in Al-Mg-Si alloys. Acta Mater 46:3893-3904. https://doi.org/10.1016/S1359-6454(98)00059-7

3. Buha J, Lumley RN, Crosky AG, Hono K (2007) Secondary precipitation in an Al-Mg-Si-Cu alloy. Acta Mater 55:3015-3024. https ://doi.org/10.1016/j.actamat.2007.01.006

4. Badini C, Marino F (1990) DSC study of ageing sequence in 6061 aluminum alloy-SiC whiskers composite. Mater Chem Phys 25:57-70

5. Marioara CD, Andersen SJ, Zandbergen HW, Holmestad R (2005) The influence of alloy composition on precipitates of the Al-Mg-Si system. Metall Mater Trans A Phys Metall Mater Sci 36:691-702. https://doi.org/10.1007/s11661-005-1001-7

6. Dutta I, Allen SM (1991) A calorimetric study of precipitation in commercial aluminium alloy 6061. J Mater Sci Lett 10:323-326. https://doi.org/10.1007/BF02670289

7. Zajac S, Bengtsson B, Jönsson C (2002) Influence of cooling after homogenisation and reheating to extrusion on extrudability and final properties of AA 6063 and AA6082 alloys. Mater Sci Forum 396-402:399-404. https://doi.org/10.4028/www.scien tific.net/msf.396-402.399

8. Sagalowicz L, Lapasset G, Hug G (1996) Transmission electron microscopy study of a precipitate which forms in the Al-Mg-Si system. Philos Mag Lett 74:57-66. https://doi. org/10.1080/095008396180407

9. Jacobs MH (1972) The structure of the metastable precipitates formed during ageing of an Al-Mg-Si alloy. Philos Mag 26:1-13. https://doi.org/10.1080/14786437208221015

10. Vargas JA, Torres JE, Pacheco JA, Hernandez RJ (2013) Analysis of heat input effect on the mechanical properties of
Al-6061-T6 alloy weld joints. Mater Des 52:556-564. https://doi. org/10.1016/j.matdes.2013.05.081

11. Dutta I, Allen SM, Hafley JL (1991) Effect of reinforcement on the aging response of cast $6061 \mathrm{Al}-\mathrm{Al}_{2} \mathrm{O}_{3}$ particulate composites. Metall Trans A Phys Metall Mater Sci 22A:2553-2563. https:// doi.org/10.1007/bf02851349

12. Pogatscher $\mathrm{S}$, Antrekowitsch $\mathrm{H}$, Leitner $\mathrm{H}$, Ebner $\mathrm{T}$, Uggowitzer PJ (2011) Mechanisms controlling the artificial aging of Al-MgSi Alloys. Acta Mater 59:3352-3363. https://doi.org/10.1016/j. actamat.2011.02.010

13. Milagre MX, Donatus U, Mogili NV, Machado CSC, Araujo JVS, Klumpp RE, Fernandes SMC, de Souza JAB, Costa I (2020) Effects of picture frame technique (PFT) on the corrosion behavior of 6061 aluminum alloy. J Nucl Mater 539:152320

14. Withers PJJ, Bhadeshi HKDHKDH (2001) Residual stress part 1measurement techniques. Mater Sci Technol 17:355-365. https ://doi.org/10.1179/026708301101510087

15. Withers PJ, Bhadeshia HKDH (2001) Residual stress part 2nature and origins. Mater Sci Technol 17:366-375. https://doi. org/10.1016/s0160-4120(16)30771-1

16. Florea RS, Hubbard CR, Solanki KN, Bammann DJ, Whittington WR, Marin EB (2012) Quantifying residual stresses in resistance spot welding of 6061-T6 aluminum alloy sheets via neutron diffraction measurements. J Mater Process Technol 212:2358-2370. https://doi.org/10.1016/j.jmatprotec.2012.06.024

17. Woo W, Feng Z, Wang XL, Brown DW, Clausen B, An K, Choo H, Hubbard CR, David SA (2007) In situ neutron diffraction measurements of temperature and stresses during friction stir welding of 6061-T6 aluminium alloy. Sci Technol Weld Join 12:298303. https://doi.org/10.1179/174329307X197548

18. Woo W, Feng Z, Wang XL, An K, Bailey WB, David SA, Hubbard $\mathrm{CR}, \mathrm{Choo} \mathrm{H}$ (2006) Feasibility of thermal strain measurements during quasi-steady state using neutron diffraction. Mater Sci Forum 524-525:387-392. https://doi.org/10.4028/www.scien tific.net/msf.524-525.387

19. Dye D, Stone HJ, Watson M, Rogge RB (2014) Characterization of phase transformations and stresses during the welding of a ferritic mild steel. Metall. Mater Trans A Phys Metall Mater Sci 45:2038-2045. https://doi.org/10.1007/s11661-013-2157-1

20. Ogawa D, Kakiuchi T, Hashiba K, Uematsu Y (2019) Residual stress measurement of $\mathrm{Al} /$ steel dissimilar friction stir weld. Sci Technol Weld Join 24:685-694. https://doi.org/10.1080/13621 718.2019.1588521

21. Woo W, Choo H, Brown DW, Feng Z (2007) Influence of the tool pin and shoulder on microstructure and natural aging kinetics in a friction-stir-processed 6061-T6 aluminum alloy. Metall Mater Trans A Phys Metall Mater Sci 38:69-76. https://doi.org/10.1007/ s11661-006-9034-0

22. Woo W, Choo H (2011) Softening behaviour of friction stir welded Al 6061-T6 and Mg AZ31B alloys. Sci Technol Weld Join 16:267-272. https://doi.org/10.1179/1362171811Y.0000000016

23. Lee SY, Ling J, Wang S, Ramirez-Rico J (2017) Precision and accuracy of stress measurement with a portable $X$-ray machine using an area detector. J Appl Crystallogr 50:131-144. https:// doi.org/10.1107/S1600576716018914

24. Cakmak E, Gussev MN, Sridharan N, Seren MH, An K, Wang H, Terrani KA (2020) Micromechanical and microstructure analysis of strain-induced phenomena in ultrasonic additively-manufactured Al-6061 alloy. Mater Sci Eng A. https://doi.org/10.1016/j. msea.2019.138533

25. Woo W, Choo H, Brown DW, Vogel SC, Liaw PK, Feng Z (2006) Texture analysis of a friction stir processed 6061-T6 aluminum alloy using neutron diffraction. Acta Mater 54:3871-3882. https ://doi.org/10.1016/j.actamat.2006.04.018

26. Bardel D, Nelias D, Robin V, Pirling T, Boulnat X, Perez M (2016) Residual stresses induced by electron beam welding in a 6061 
aluminium alloy. J Mater Process Technol 235:1-12. https://doi. org/10.1016/j.jmatprotec.2016.04.013

27. Saleh M, Luzin V, Spencer K (2014) Analysis of the residual stress and bonding mechanism in the cold spray technique using experimental and numerical methods. Surf Coat Technol 252:15-28. https://doi.org/10.1016/j.surfcoat.2014.04.059

28. Saleh M, Luzin V, Spencer K (2014) Evaluation of the residual stress in the cold spray technique using Smooth Particle Hyrodynamics modelling and neutron diffraction. Mater Sci Forum 777:205-212. https://doi.org/10.4028/www.scientific.net/ MSF.777.205

29. Chen CM, Kovacevic R (2003) Finite element modeling of friction stir welding - thermal and thermomechanical analysis. Int J Mach Tools Manuf 43:1319-1326. https://doi.org/10.1016/S0890 -6955(03)00158-5

30. Lee SY, Skorpenske H, Stoica AD, An K, Wang XL, Noyan IC (2014) Measurement of interface thermal resistance with neutron diffraction. J Heat Transf 136:1-12. https://doi.org/10.1115/1.40255 00

31. Woo W, Feng Z, Wang XL, Hubbard CR (2009) Neutron diffraction measurements of time-dependent residual stresses generated by severe thermomechanical deformation. Scr Mater 61:624627. https://doi.org/10.1016/j.scriptamat.2009.05.040

32. Chen $Y$, Jiang $Y$, Zhang F, Ding H, Zhao J, Ren Z (2018) Water cooling effects on the microstructural evolution and mechanical properties of friction-stir-processed Al-6061 alloy. Trans Indian Inst Met 71:3077-3087. https://doi.org/10.1007/s1266 6-018-1453-2

33. Wang HQ, Sun WL, Xing YQ (2013) Microstructure analysis on 6061 aluminum alloy after casting and diffuses annealing process. Phys Procedia 50:68-75. https://doi.org/10.1016/j.phpro .2013 .11 .013
34. Zhao QL, Shan TT, Geng R, Zhang YY, He HY, Qiu F, Jiang QC (2019) Effect of preheating temperature on the microstructure and tensile properties of 6061 aluminum alloy processed by hot rolling-quenching. Metals (Basel). https://doi.org/10.3390/ met9020182

35. Rajabi F, Zarei-Hanzaki A, Eskandari M, Khoddam S (2013) The effects of rolling parameters on the mechanical behavior of 6061 aluminum alloy. Mater Sci Eng A 578:90-95. https://doi. org/10.1016/j.msea.2013.04.023

36. Hurley ND, Van Geertruyden WH, Misiolek WZ (2009) Surface grain structure evolution in hot rolling of 6061 aluminum alloy. J Mater Process Technol 209:5990-5995. https://doi. org/10.1016/j.jmatprotec.2009.07.019

37. Johansson J, Ode M (1999) Evolution of the residual stress state in a duplex stainless steel during loading. Acta Mater 47:2669-2684

38. Milagre MX, Donatus U, Maria R, Silva P, Victor J, Araujo S, Souto RM, Costa I (2020) Galvanic coupling effects on the corrosion behavior of the 6061 aluminum alloy used in research nuclear reactors. J Nucl Mater 541:152440. https://doi.org/10.1016/j. jnucmat.2020.152440

39. Honarpisheh M, Nazari F, Haghighi MA (2020) Annealing heat treatment effect on the residual stresses in hot-extruded aluminum alloy rods with high cross-sectional reduction. Strength Mater 52:291-302. https://doi.org/10.1007/s11223-020-00177-8

Publisher's Note Springer Nature remains neutral with regard to jurisdictional claims in published maps and institutional affiliations. 